\title{
FIRST REPORT OF COEXISTENCE OF AmpC BETA-LACTAMASE GENES IN KLEBSIELLA PNEUMONIAE STRAINS ISOLATED FROM BURN PATIENTS
}

\author{
ROYA GHANAVATI ${ }^{1}$, DAVOOD DARBAN-SAROKHALIL ${ }^{1}$, FATEME \\ NAVAB-MOGHADAM $^{1}$, HOSSEIN KAZEMIAN ${ }^{2,3}$, GHOLAMREZA IRAJIAN ${ }^{1}$ and \\ SHABNAM RAZAVI ${ }^{1 *}$ \\ ${ }^{1}$ Department of Microbiology, School of Medicine, Iran University of Medical Sciences, \\ Tehran, Iran \\ ${ }^{2}$ Clinical Microbiology Research Center, Ilam University of Medical Sciences, Ilam, Iran \\ ${ }^{3}$ Department of Microbiology, School of Medicine, Tehran University of Medical \\ Sciences, Tehran, Iran
}

(Received: 27 December 2016; accepted: 26 May 2017)

\begin{abstract}
Klebsiella spp. are among the most frequently isolated bacteria from burn wounds. These organisms are among the most important opportunistic pathogens, causing hospital-acquired and healthcare-associated infections worldwide. Limited information is available about prevalence of AmpC-producing Klebsiella pneumoniae from burn patients. Therefore, the aim of this study was to determine the characterization of AmpC beta-lactamase among K. pneumoniae isolated from burn patients. Samples were collected from wound specimens of patients with burn injury from a burn hospital in Tehran during 18 months (March 2015 to August 2016). For phenotypic detection of AmpC beta-lactamase, disk diffusion method with cefoxitin was used for screening, AmpC disk test and boronic acid inhibitor-based method were used as confirmatory tests. Polymerase chain reaction (PCR) was performed to screen all isolates with AmpC genes including ACCM, DHAM, EBCM, FOXM, MOXM, and CITM. Finally, PCR products were validated using sequencing. During this study, 102 isolates of K. pneumoniae were collected. Among these isolates, $52.9 \%$ suspected as AmpC producer by disk agar diffusion cefoxitin screening method. By confirmatory phenotypic methods, $19.6 \%$ of isolates considered as AmpC producer. Molecular analysis revealed $43.1 \%$ of cefoxitin-resistant isolates harbored at least one of the AmpC genes including CITM (22.5\%), EBCM (21.5\%), DHAM (7.8\%), and FOXM $(0.98 \%)$. In addition, $5.8 \%$ of isolates harbored two AmpC genes and $2.9 \%$ harbored three AmpC genes. In conclusion, K. pneumoniae is becoming a serious problem in burn patients. Accurate and precise methods and guidelines should be designed for detection of antibiotic-resistant mechanisms. Our data showed the high rate of AmpC
\end{abstract}

*Corresponding author; E-mail: razavi.sh@iums.ac.ir 
beta-lactamase among $K$. pneumoniae isolated from burn patients, which limit the treatment options. Therefore, the results of this study can provide evidence to help for appropriate treatment of burn patients.

Keywords: K. pneumoniae, beta-lactamase, AmpC, burn wounds

\section{Introduction}

In comparison with different type of nosocomial infections among hospitalized patients, burn patients are more susceptible to nosocomial infections because of their immunocompromised state. In this situation, antibacterial treatments of these patients are important in burn wards. For example, choosing the best antibiotic regimens is a crucial means of infections prevention and control. Unfortunately, during recent decades the widespread use of antibiotics led to the emergence of drug-resistant bacteria, such as multidrug and extensively drugresistant organisms. Thus in that area, precise knowledge of the bacterial resistance patterns is essential for determining the best antibiotic regimens or empirical therapy in critical conditions, for treatment of burn patients [1].

Klebsiella spp. are among the most frequently isolated bacteria from burning wounds [2]. This organism is one of the most important opportunistic pathogens, causing hospital-acquired and healthcare-associated infections worldwide [3]. In recent decades, due to its tendency to develop antibiotic resistance and increasing virulence factor, lead to emerging this bacterium as clinically important organism [4, 5]. Klebsiella pneumoniae strains commonly have different types of beta-lactamase enzymes such as extended-spectrum beta-lactamases (ESBLs), AmpC beta-lactamases, and carbapenemases, which confer resistance to different types of beta-lactam antibiotics [6]. The AmpC beta-lactamases are particularly troublesome group because can easily be transmitted by conjugation to other bacteria, which has increased incidence worldwide [7]. According to the Ambler classification, AmpCs belong to Class C beta-lactamase. AmpC genes may be located on chromosome or plasmids. In addition to resistance to penicillins and most cephalosporins, unlike ESBLs, AmpC-producing organisms can degrade cephamycins [8]. AmpC beta-lactamase-producing organisms show more extensive antibiotic resistance features in comparison with other ESBLs-producing organisms [9]. It has been reported that AmpC beta-lactamase can confer resistance to cefepime (fourth-generation cephalosporin antibiotic) and also can increase the minimum inhibitory concentration (MIC) value of carbapenems $[9,10]$.

With respect to clinically important $\mathrm{AmpC}$-producing strains, standard guidelines do not introduce the ideal test for AmpC detection. However, polymerase chain reaction (PCR) remains the gold standard for the detection of AmpC beta-lactamases [11]. 
Thus, due to the lack of standard guiding principle for the revealing of $\mathrm{AmpC}$, little is known about the prevalence of AmpC-producing K. pneumoniae among burn patients, which early detection and identification of AmpC lead to implementation of the ideal antimicrobial therapy, and also may allow infectious control measures to be introduced to prevent spread of drug-resistant organisms. Therefore, the aim of this study was to determine the characterization of AmpC beta-lactamase among $\mathrm{K}$. pneumoniae isolated from burn patients by phenotypic and genotypic methods.

\section{Materials and Methods}

\section{Bacterial strains}

This study was a cross-sectional study. Samples were collected from wound specimens of patients with burn injury from a burn hospital in Tehran, Iran during 18 months (March 2015 to August 2016). Phenotypic identification and biochemical validations performed for $K$. pneumoniae detection according to medical laboratory guidelines.

\section{Phenotypic detection of AmpC beta-lactamase}

For screening of AmpC beta-lactamase disk diffusion method with cefoxitin, amoxicillin-clavulanate, cefotaxime, and ceftazidime antibiotic disks was performed according to the guidelines of Clinical and Laboratory Standards Institute [12]. The isolates, which were resistant to all of the disks considered as AmpC producer. Then confirmatory tests, such as AmpC disk test, boronic acid inhibitor-based method were performed [13, 14]. K. pneumoniae ATCC 700603 was used as standard strain.

\section{Molecular analysis of AmpC}

For molecular evaluation, the boiling method was used for extracting DNA. PCR was performed to screen all isolates with AmpC genes including ACCM, DHAM, EBCM, FOXM, MOXM, and CITM. Specific primers were used for each gene (Table I) [15]. PCR was performed by thermal cycler (Eppendorf, Mastercycler gradient). PCR was carried out in a total volume of $25 \mu \mathrm{l}$ containing $2 \mathrm{mM} \mathrm{MgCl}_{2}, 1 \mu \mathrm{l}$ PCR buffer, $2 \mathrm{mM}$ dNTPs, 1 pmol of primers, $0.25 \mathrm{U}$ Taq DNA polymerase (CinnaGen Co., Iran), and $5 \mu$ of template DNA. PCR products were 
Table I. Specific primers for detection of AmpC genes

\begin{tabular}{llcc}
\hline Gene name & \multicolumn{1}{c}{ Primers } & $\begin{array}{c}\text { Annealing } \\
\text { temperature }\left({ }^{\circ} \mathrm{C}\right)\end{array}$ & $\begin{array}{c}\text { Product } \\
\text { size }(\mathrm{bp})\end{array}$ \\
\hline ACCM & $\begin{array}{l}\text { F-AAC AGC CTC AGC AGC CGG TTA } \\
\text { R-TTC GCC GCA ATC ATC CCT AGC }\end{array}$ & 58.6 & 346 \\
DHAM & F-AAC TTT CAC AGG TGT GCT GGGT & 60 & 405 \\
EBCM & R-CCG TAC GCA TAC TGG CTT TGC & 63 \\
FOXM & F-TCG GTA AAG CCG ATG TTG CGG & 63 & 190 \\
MOXM & R-CTT CCA CTG CGG CTG CCA GTT & 59 \\
F-AAC ATG GGG TAT CAG GGA GATG & R-CAA AGC GCG TAA CCG GAT TGG & 63 & 520 \\
& F-GCT GCT CAA GGA GCA CAG GAT & 63 & 426 \\
\hline
\end{tabular}

analyzed by electrophoresis on $1 \%(\mathrm{w} / \mathrm{v})$ agarose gel (Merck, Germany) containing ethidium bromide and the gels were visualized under UV light irradiation (Gel Doc $\left.{ }^{\mathrm{TM}} \mathrm{XR}+, \mathrm{USA}\right)$. Finally, PCR products were validated using sequencing (Bioscience Co., UK).

\section{Results}

During this study, 102 isolates of $K$. pneumoniae were collected from burn wound infections. Among these isolates, 52.9\% $(n=54)$ suspected as AmpC producer by disk agar diffusion (DAD) cefoxitin screening method. By confirmatory phenotypic methods for detection of AmpC, 19.6\% $(n=20)$ of isolate considered as AmpC producer (Figure 1).

Molecular analysis revealed $43.1 \%(n=44)$ of isolates harbored at least one of the AmpC genes including CITM 22.5\% $(n=23)$, EBCM 21.5\% $(n=22)$, DHAM 7.8\% $(n=8)$, and FOXM 0.98\% $(n=1)$ (Table II). In addition, $5.8 \%$ $(n=6)$ of isolates harbored two AmpC genes and 2.9\% $(n=3)$ harbored three AmpC genes (Table III).

\section{Discussion}

In this study, the prevalence of AmpC-producing K. pneumoniae isolates among burn wound infections was evaluated by phenotypic and genotypic methods. By cefoxitin screening method, $52 \%$ of isolates suspected as AmpC 


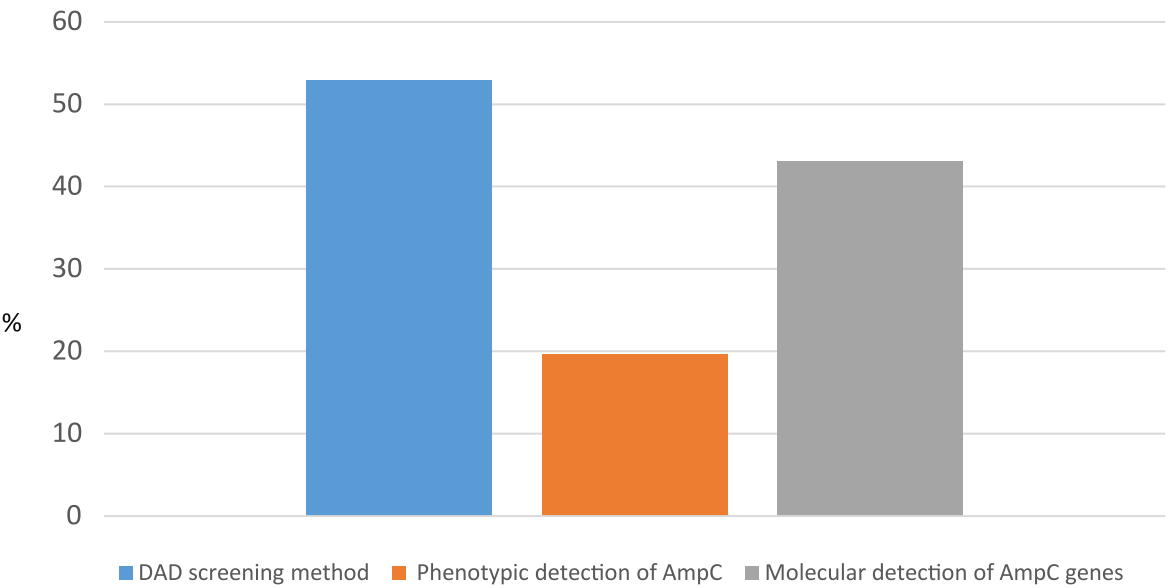

Figure 1. Compression of different methods for AmpC beta-lactamase detection

Table II. Distribution of AmpC genes among clinical isolates of K. pneumoniae

\begin{tabular}{lllrl}
\hline Distribution of AmpC genes & CITM & EBCM & DHAM & FOXM \\
\hline$\%$ of isolates $(N)$ & $22.5(23)$ & $21.5(22)$ & $7.8(8)$ & $0.98(1)$ \\
$\%$ of isolates among AmpC producer $(N)$ & $52.2(23)$ & $50(22)$ & $18.1(8)$ & $2.2(1)$ \\
\hline
\end{tabular}

Table III. Coexistence of AmpC genes among clinical isolates of $K$. pneumoniae

\begin{tabular}{lcccc}
\hline Coexistence of AmpC genes & $\begin{array}{c}\text { CITM and } \\
\text { DHAM }\end{array}$ & $\begin{array}{c}\text { CITM and } \\
\text { EBCM }\end{array}$ & $\begin{array}{c}\text { EBCM and } \\
\text { DHAM }\end{array}$ & $\begin{array}{c}\text { CITM, DHAM, } \\
\text { and EBCM }\end{array}$ \\
\hline $\begin{array}{l}\% \text { of isolates }(N) \\
\% \text { of isolates among AmpC } \\
\text { producer }(N)\end{array}$ & $1.9(2)$ & $2.9(3)$ & $0.98(1)$ & $1.9(2)$ \\
\hline
\end{tabular}

producer, but by confirmatory methods just $19 \%$ of isolates considered as AmpC producer. Molecular analysis revealed that $43 \%$ of isolates harbor AmpC beta-lactamase genes. In our analysis, high rate of false negative results was seen in phenotypic detection methods. But, cefoxitin was more sensitive than phenotypic methods. Any AmpC genes were not detected in the ten cefoxitin-resistant strains. One reason for this phenotypic resistance is due to loss of outer membrane porins [16]. 
Our analysis revealed the high prevalence of $\mathrm{AmpC}$ beta-lactamase among clinical isolates of K. pneumoniae isolated from burn patients. According to Azimi et al.'s study during 2013 in Iran, the prevalence of AmpC beta-lactamase among clinical isolates of K. pneumoniae was reported 1.6\% [17]. Our data showed the sharp rise of AmpC beta-lactamase incidence over the past 3 years. Some studies have showed that AmpC beta-lactamases are produced in upward of $50 \%$ of clinical isolates [18-20]. A limited number of antibiotic treatment options are available in infections caused by AmpC-producing K. pneumoniae. Carbapenems have emerged as a primary agent for management of infections due to AmpCproducing K. pneumoniae [9]. However, it has been reported that AmpC betalactamase can increase the MIC value of carbapenems and confer resistance to this class of antibiotics $[10,11]$.

Japoni-Nejad et al. [21] during 2014 in Iran showed that 19\% of clinical isolates of K. pneumoniae harbor AmpC genes. Of this 19\%, 42.2\% carried CITM gene, $36.8 \%$ carried MOX gene, whereas $15.7 \%$ and $5.2 \%$ carried $\mathrm{EBCM}$ and DHAM genes, respectively. According to our data, the most AmpC genes prevalent among the $K$. pneumoniae isolated from burn infections are CITM and $\mathrm{EBCM}$, respectively. Our data reveal that shifting the prevalence of AmpC genes occurred during the short time in our country. In addition, according to Jean et al.'s [22] study, the most abundant $\mathrm{AmpC}$ beta-lactamase variant among clinical isolates of $K$. pneumoniae in Asia-Pacific region was DHAM.

In our analysis, eight strains were found which coharbored at least two AmpC genes. Two of these isolates were coharbored three AmpC genes. Therefore, this study is the first report of coexistence of AmpC genes in clinical isolates of $K$. pneumoniae.

In conclusion, $K$. pneumoniae is becoming a serious problem in burn patients. Accurate and precise methods and guidelines should be designed for detection of antibiotic resistance mechanisms. Our data showed high rate of AmpC beta-lactamase among K. pneumoniae isolated from burn patients, which limit the treatment options. Therefore, the results of this study provide evidence to help for appropriate treatment of burn patients. Infection control programs and strict antimicrobial stewardship policies should be applied to reduce the prevalence of these high-risk strains. Finally, using the antibacterial activities of medicinal plants with low level of toxicity can improve treatment of infection due to drug-resistant organisms $[23,24]$.

\section{Conflict of Interest}

The authors declare that there is no conflict of interest. 


\section{References}

1. Wang, L. F., Li, J. L., Ma, W. H., Li, J. Y.: Drug resistance analysis of bacterial strains isolated from burn patients. Genet Mol Res 13, 9727-9734 (2005).

2. Mehta, M., Dutta, P., Gupta, V.: Bacterial isolates from burn wound infections and their antibiograms: A eight-year study. Indian J Plast Surg 40, 25 (2007).

3. Seifi, K., Kazemian, H., Heidari, H.: Evaluation of biofilm formation among Klebsiella pneumoniae isolates and molecular characterization by ERIC-PCR. Jundishapur J Microbiol 9, e30682 (2016).

4. Nordmann, P., Cuzon, G., Naas, T.: The real threat of Klebsiella pneumoniae carbapenemaseproducing bacteria. Lancet Infect Dis 9, 228-236 (2009).

5. Melegh, S., Schneider, G., Horváth, M., Jakab, F., Emődy, L., Tigyi, Z.: Identification and characterization of CTX-M-15 producing Klebsiella pneumoniae clone ST101 in a Hungarian university teaching hospital. Acta Microbiol Immunol Hung 62, 233-245 (2015).

6. Sanchez, G. V.: Klebsiella pneumoniae antimicrobial drug resistance, United States, 1998-2010. Emerg Infect Dis 19, 133-136 (2013).

7. Shaikh, S., Fatima, J., Shakil, S.: Antibiotic resistance and extended spectrum betalactamases: Types, epidemiology and treatment. Saudi J Biol Sci 22, 90-101 (2015).

8. D'Angelo, R. G., Johnson, J. K., Bork, J. T.: Treatment options for extended-spectrum betalactamase (ESBL) and AmpC-producing bacteria. Expert Opin Pharmacother 17, 953-967 (2016).

9. Liu, X. Q., Liu, Y. R.: Detection and genotype analysis of AmpC $\beta$-lactamase in Klebsiella pneumoniae from tertiary hospitals. Exp Ther Med 12, 480-484 (2016).

10. Hsieh, W. S., Wang, N. Y., Feng, J. A.: Identification of DHA-23, a novel plasmidmediated and inducible AmpC beta-lactamase from Enterobacteriaceae in Northern Taiwan. Front Microbiol 6, 436 (2015).

11. Helmy, M. M., Wasfi, R.: Phenotypic and molecular characterization of plasmid mediated AmpC $\beta$-lactamases among Escherichia coli, Klebsiella spp., and Proteus mirabilis isolated from urinary tract infections in Egyptian hospitals. Biomed Res Int 2014, 171548 (2014).

12. Wang, Y., Lv, Y., Cai, J.: A novel gene, optrA, that confers transferable resistance to oxazolidinones and phenicols and its presence in Enterococcus faecalis and Enterococcus faecium of human and animal origin. J Antimicrob Chemother 70, 2182-2190 (2015).

13. Black, J. A., Moland, E. S., Thomson, K. S.: AmpC disk test for detection of plasmidmediated AmpC $\beta$-lactamases in Enterobacteriaceae lacking chromosomal AmpC $\beta$-lactamases. J Clin Microbiol 43, 3110-3113 (2005).

14. Coudron, P. E.: Inhibitor-based methods for detection of plasmid-mediated AmpC $\beta$-lactamases in Klebsiella spp., Escherichia coli, and Proteus mirabilis. J Clin Microbiol 43, 4163-4167 (2005).

15. Pérez-Pérez, F. J., Hanson, N. D.: Detection of plasmid-mediated AmpC $\beta$-lactamase genes in clinical isolates by using multiplex PCR. J Clin Microbiol 40, 2153-2162 (2002).

16. Jacoby, G. A.: AmpC $\beta$-lactamases. Clin Microbiol Rev 22, 161-182 (2009).

17. Azimi, L., Erajiyan, G., Talebi, M.: Phenotypic and molecular characterization of plasmid mediated AmpC among clinical isolates of Klebsiella pneumoniae isolated from different hospitals in Tehran. J Clin Diagn Res 9, DC01 (2015). 
18. Doddaiah, V., Anjaneya, D.: Prevalence of ESBL, AmpC and carbapenemase among Gram negative bacilli isolated from clinical specimens. Am J Life Sci 2, 76-81 (2014).

19. Grover, N., Sahni, A. K., Bhattacharya, S.: Therapeutic challenges of ESBLS and AmpC beta-lactamase producers in a tertiary care center. Med J Armed Forces India 69, 410 (2013).

20. Grover, N., Sahni, A. K., Bhattacharya, S.: Therapeutic challenges of ESBLS and AmpC beta-lactamase producers in a tertiary care center. Med J Armed Forces India 69, 4-10 (2013).

21. Japoni-Nejad, A., Ghaznavi-Rad, E., van Belkum, A.: Characterization of plasmid-mediated AmpC and carbapenemases among Iranain nosocomial isolates of Klebsiella pneumoniae using phenotyping and genotyping methods. Osong Public Health Res Perspect 5, 333-338 (2014).

22. Jean, S. S., Hsueh, P. R., Korman, T.: Distribution of ESBLs, AmpC $\beta$-lactamases and carbapenemases among Enterobacteriaceae isolates causing intra-abdominal and urinary tract infections in the Asia-Pacific region during 2008-14: Results from the Study for Monitoring Antimicrobial Resistance Trends (SMART). J Antimicrob Chemother 72, 166171 (2017).

23. Saidi, M., Sadeghifard, N., Kazemian, H.: Ex vivo evaluation of thymus daenensis as an antioxidant and antibacterial medicinal herb. Drug Res 66, 657-659 (2016).

24. Kazemian, H., Ghafourian, S., Heidari, H., Amiri, P., Yamchi, J. K., Shavalipour, A., Houri, H., Maleki, A., Sadeghifard, N.: Antibacterial, anti-swarming and anti-biofilm formation activities of Chamaemelum nobile against Pseudomonas aeruginosa. Rev Soc Bras Med Trop 48, 432-436 (2015). 